\title{
9 Translation of Studies
}

While all participants in the translation group made up in chapter 8 cling to the centrality of text, some start to think that it is possible to look beyond texts on paper. They figure out how to penetrate the realm of big data. Although today we think in terms of text corpora that are available online, i.e., everywhere, it is worth recalling the importance of the translatio textuum, the actual movements of books that took place during the past centuries:

the circulation of books in all its material aspects (from printing to official and underground retail) is also a non-marginal aspect of the translatio studiorum, which is endowed with its own agents and ways of communication. Testimony to this is provided by the many letters mirroring interests, friendships, and tensions within the Respublica litterarum, with all pressing requests and searches for, and exchanges of new, rare or prohibited books.... When, on May 10, 1933, Hitler ordered the burning of books by "degenerate" authorsKarl Marx and Sigmund Freud, Thomas Mann and Erich M. Remarque-on the squares in front of the Reich's universities, those malevolent bonfires triggered a new series of migrations of men and books, a new translatio on the path of freedom. Beyond the voluntary exiles, the daring transfer of the library of the Warburg Institute from Hamburg to London by two boats that landed on the shores of the Thames in December 1933 is paradigmatic: sixty thousand volumes, documents, and photographs from a great school that had profoundly altered and renewed research into iconology, art history, and the history of ideas. It was not merely a library, it was a cultural patrimony, a school of research that landed in London, thus setting off a new translatio in a climate of uncertainty and hope. (Gregory 2012, 19-21)

Books are preserved in libraries. Libraries are public spaces, and such are museums, science centers, and any place in which co-creation activities may occur. Research infrastructures such as DARIAH are excellent examples because they foster new ways of knowledge production inside research performing organizations, which are influenced by and influence the engagement of the humanities with society at large.

In this chapter, I look into cultural diversity and intercultural dialogue as political facts that need to be addressed as objects of multilevel governance of society by providing spaces of exchange in which citizens engage in the process of sharing experiences while appropriating common goods content. For such crossfertilization, many institutions that make public spaces possible must be taken into consideration.

Ә OpenAccess. (c) 2021 Riccardo Pozzo, published by De Gruyter. (cc))BY-NC-ND This work is licensed under the Creative Commons Attribution-NonCommercial-NoDerivatives 4.0 International License. 


\subsection{Across Boundaries}

The melting pot of diverse experiences and myths sets the stage for the theme of the translatio studiorum, which is variously connected with the translatio imperii (Curtius 1948, 36; 2013, 710). The succession of the reigns is also the succession of cultures, the former and the latter being placed under the protection and the guidance of the great astral conjunctions (Gregory 2012, 8). Think of the cargos on the ships of Gaiseric, the king of the Vandals and Andals, that in the aftermath of the sack of Rome in the Summer of 455 brought to Carthage gold, silver, and many many books. The transmission of texts takes place as a balance to its opposite, i.e., the destruction of texts like the ones ordered by Savonarola at the end of the fifteenth century in Florence or during the thirties of the last century by the Nazis, which culminated with the setting ablaze of the special collections of the National Library in Warsaw as a part of the repression in the aftermath of the uprising of August 1944-a fire that destroyed most sources of the origins of the Polish language. Another example was the impossibility of circulating specific texts within the USSR and letting texts from the USSR reach the West, which called for the remedy of the clandestine transmission of cyclostyled prints (Leonardi 2012, 68).

Philosophical terminology is present in a considerable number of languages of culture, starting with a series of different texts written mainly between the sixth and the eleventh century, in a wide geographical area that extends from Western Europe to India-not to mention the traces left even further to the East, in China. Philosophical terminology deserves to be the subject of an effort to reflect and compare at the glottological and historical-linguistic levels (Zonta 2018, 9). Migrating texts (Sweet 2011) are written on migrating alphabets, which is the primary material of the Lessico Intellettuale Europeo (Gregory et al. 19672021).

Occupation and emigration forcefully have internationalized intellectual history. First and foremost, however, migration has also intensified the transfer of ideas and knowledge, and it has helped foster international communication and interdisciplinary understanding (Schneider 2005, 151). We can talk of "exile historiography," of a "refugee historian," and of an "exile historian" (Berger and De Baets 2016, 13). Comparative history of philosophy (Panikkar 1988) clarifies the extent to which the cultures of a limited historical period and a restricted area have been in contact with each other, directly or indirectly. It is time to look at plurality (Diagne 2018). Comparative history of ideas has been the first step towards a global history of ideas in which the development of ideas should be viewed in the global scope (Nakamura 1986). Mou Zongsan's (2014) Post-Kant- 
ian Confucian metaphysics was among the first to implement the merging of Western and Chinese traditions (Tu Xiaofei 2007).

The task is to identify the phenomena of transferring and transcribing a cultural experience from one to the other historical and geographic context, following the prevailing of diverse cultural and political supremacies. The fact is, every time a language was written down, it was the result of a migratory phenomenon. It matters little whether according to the legend accepted until the end of the

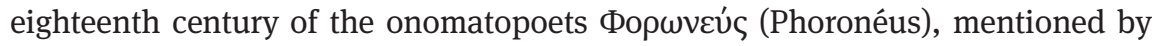
Plato (1998) in the Timaeus (Tí $\mu \alpha \iota$-23b) and Adam (Genesis 2, 20) that, when they transliterated the phonemes of the first human language, they first did it into ideograms and then into alphabets or vice-versa (Gregory 2006, 32). As Bronisław Malinowski put it:

We need a theory of culture, of its processes and products, of its specific determinism, of its relation to basic facts of human psychology and the organic happening within the human body. Such a theory is by no means the monopoly of the anthropologist. He has, however, a special contribution to make, and this may provoke corresponding efforts on the part of the empirically-minded historians, sociologists, psychologists and students of specific type-activities, legal, economic, or educational. (Malinowski 1944, 12-13)

All Latin Medieval civilization is a continuous acquisition and interpretation. Each translation is an interpretation of works of ancient pagan civilization and from distant cultures-Greek, Byzantine, Arab, Chinese-to transfer their competencies and studies (Gregory 2012,1). The notion of a culture of interculturality accompanies all cultures "like a shadow and hinders them from absolutizing themselves" (Mall 2000, 9). The declaration unanimously adopted by the ministers of culture of 180 countries during the International Conference of Culture Ministers of 31 July-4 August 2015 organized by the Italian Ministry of Cultural Heritage, Cultural Activities and of Tourism at Expo 2015 in Milan states that:

Cultural heritage is the mirror of history, civilization and of the society which is expected to protect it. Cultural heritage, both tangible and intangible, is also the essence of identity, the memory of peoples and their past and present civilizations. It expresses, at the same time, universally recognized values of tolerance, dialogue and mutual understanding ... the work of man and his extraordinary talent must be protected and preserved for the benefit of future generations. (MIBACT 2014).

In the globalized world of the near future, the idea of the plurality of translationes studiorum makes mutual enrichment possible. We must learn to embrace an intercultural identity rather than an arbitrary thick cultural identity (Geertz 1973, 3-30). 


\subsection{Spaces for Exchange}

In our quickly changing society, we face issues of multiculturalism and migration, innovation and sustainability, security and freedom. In recent years, inclusion has become one of the most dominant values and objectives in education (Felder 2018, 54). Intercultural competencies are about awareness-raising (EAC 2014, 52). Intercultural dialogue encourages an advanced, broad-spectrum multidisciplinary discussion of the issues taken into consideration to define a specific scientific reference framework. The aim is to provide tools to overcome prejudices and encourage a more conscious and thoughtful reflection on the issues of pluralism while offering sector operators and policymakers a clear and specific vision for their actions and choices.

There is a consensus that a "broader concept of commitment to social inclusion through the arts" is to be wished for. Because "there is no audience in intercultural dialogue," while "intercultural work means a process of co-creation." This is due to the reason that "access, participation, and co-creation are preconditions for achieving intercultural dialogue in practice” (EAC 2014, 91). Due to the challenges of access and limits in libraries as public spaces, especially an architecture of openness that lets the outside in (Mickiewicz 2016, 238), the process of creating spaces of exchange requires programming, staffing, and boards, reaching out to new audiences, creating spaces for encounter, and results in intercultural sensitivity and competencies, which are cultural innovation outcomes (EAC 2014, 25; see above chapter 6).

I am talking of spaces for exchange, i.e., public spaces such as libraries, museums, science centers, and digital libraries in multiple languages (EAC 2014, 9). We are now in the twenty-first century, and we can do so much better than we used to do. We rely already on hypertexts that provide metadata-rich and fully interoperable sources, translations, bibliographies, indexes, lexica, and encyclopedias. Users begin at the top level by perusing general narratives. They follow the links to critical editions, their translations in many languages, articles, indices, and monographs. In sum, spaces for exchange are, most importantly, research infrastructures that allow users to engage in access, participation, and co-creation. The research infrastructures I have presented in chapter 7 serve as hubs in so far as they facilitate all services of virtual and instrumental access to data, simulations, and best practices as well as government-led activities: e.g., satellites and topographical techniques, drones and sensors for heritage protection in broad areas; advanced diagnostic systems; nano-materials and nano-technologies for conservation; 3D for the enhancement of cognitive access in historical and archaeological contexts; methodologies and protocols for 3D 
rendering in hazardous contexts; monitoring artifacts/context interaction; advanced exhibition systems; smart showcases.

\subsection{Humanities European Research Area}

The Humanities in the European Research Area consortium (HERA) started in 2006 and has funded five joint research program. ${ }^{138}$ It has served as a launching pad for projects on social, cultural, political, and ethical development that have generated new knowledge and enabled policymakers, researchers, and the general public to interpret a changing world's challenges. HERA is about Europe and its history. ${ }^{139}$ Being first understood as a pure geographical concept, differentiated from Asia and Africa, Europe coalesced a cultural definition only in the eighth century, signifying the new mix created through the confluence of Germanic traditions and Christian-Latin culture. ${ }^{140}$ To pose "Europe in the Mirror of World Cultures" is an exciting stage for showcasing non-European, extra-European discoveries of Europe (Mall 2000, 109). To give an idea, let me sketch the outline of HERA's last joint research project about culture, integration, and the European public space.

First, the arts and humanities are well-positioned to investigate the role of culture in integration processes-considering both successes and failures. Culture plays an essential role as a driver of human behavior, such as values, belief systems, memories, heritage, languages, educational systems, and creative practices. The cultural, political, and economic spheres exist in dynamic relation to each other. The coherence of Europe (or any such political and economic formation) is closely related to and impacted by events and practices at the level of culture.

Second, the integration of people of differing values, traditions, ethnicities, races, and gender identities within overarching frameworks such as citizenship, community, nationality, while globalization has been a long-standing challenge worldwide. Integration has been seen as a way of overcoming divisive conflicts,

$138 \mathrm{http} / / /$ heranet.info/about-us/who-we-are/, visited on 6 May 2021. The titles of the five calls so far are: JRP Ia (2009-2012): Humanities as a Source of Creativity and Innovation; JRP Ib (2009-2012): Cultural Dynamics: Inheritance and Identity; JRP II (2013-2016): Cultural Encounters; JRP III (2016-2019): Uses of the Past; JRP IV (2019-2022): Public Spaces: Culture and Integration in Europe.

139 See the museum for the history of Europe, the House of Europe. https://europarl.europa.eu/ visiting/it/visitor-offer/brussels/house-of-european-history, visited on 6 May 2021.

$140 \mathrm{http} / / /$ heranet.info/about-us/who-we-are/, visited on 6 May 2021. 
promoting tolerance and respect, and creating creative innovation. Simultaneously, it has also been argued that integration can potentially lead to disempowerment, erasure of difference, and loss of identity for some. Various models and experiences of integration exist that differ in both their aims and their effects. For example, can integration co-exist with diversity, or does it inevitably tend towards homogenization and the erasure of differences? How are power relations constructed within integration processes? At present, integration issues relate strongly to societal challenges involving inequality, disenfranchisement, intolerance, xenophobia, extremism, ethnic conflict, Euro-skepticism, and the North-South and East-West divide.

Third, a great deal of cultural integration (or resistance to integration) occurs in various public spaces where personal encounters occur, shared values and beliefs are expressed, and social and cultural institutions are made and used. Public spaces are the arenas in which critical cultural interactions and societal dynamics occur and can be observed (Metha 2015). Specifically, there is a urgent need to define public space and the role of science in enabling or problematizing integration while respecting diversity. The notion of public space can be interpreted widely: physical and built environments, landscapes, and material culture. However, it also includes cultural zones, public spheres, and virtual spaces defined by media, language, ethnicity, shared values, political allegiances, religious identities, creative practices, and communication technologies. These spaces are populated not just by people but by material objects, texts, artworks, performances, and institutions, all of which contribute to creating a sense of place. Recent research acknowledges the crucial importance of physical things, objects, and material traces of culture and the value of material culture for providing new ways of looking at multiple histories and identities. ${ }^{141}$

Summing up, HERA has asked scholars to clarify how and why the humanities talk to citizens, civil society organizations, public administrations. The humanities transfer knowledge and aim at public engagement, which ought to be evaluated just as much as technology transfer to the industry. The humanities construct cultural innovation based on social innovation. Primarily, they provide the conditions of possibility for intercultural dialogue. It is a matter of considering how ideas, cultures, traditions, and practices have come into being transmitted and diffused among different actors in different regions. It is a matter of exploring and systematizing precisely what the reflective society is in its historical

$141 \mathrm{http}: / /$ heranet.info/projects/public-spaces-culture-and-integration-in-europe/, visited on 6 May 2021. 
development, innovation, and change, a fundamental process for the human condition. ${ }^{142}$

\subsection{Equals in Dignity}

The Universal Declaration on Cultural Diversity recognizes cultural diversity as a "common heritage of mankind" and considers its preservation a concrete and ethical imperative, inseparable from respect for human dignity (UNESCO 2001, 2005). This declaration was reinforced in 2005 at Paris by the Convention on the Protection and Promotion of the Diversity of Cultural Expressions, which also talks about the goal of fostering interculturality to develop cultural interaction in the spirit of building bridges between peoples. ${ }^{143}$

The scope of the endeavor is breathtaking. It sets off from the claim stated in article 1 of the Universal Declaration of Human Rights that: "All human beings are born free and equal in dignity and rights." 144 If dignity were a property bestowed on human beings by birth, dignity could never be lost. However, in the case of dangerous criminals, Kant has expressed doubts about dignity as an inalienable property. Hence the set of questions that provide the red thread for current discussions: "Are human rights grounded in dignity so that they can be derived directly from the concept of dignity? Or does dignity in and of itself provide reasons for human rights? Is there a connecting tie between it and the legal sphere of human rights at all?” (Kato and Schönrich 2010, 1)

On top of dignity and human rights, other questions arise when it comes to defining the bearers of dignity. The notion of dignity is not limited to human beings only. It extends instead to all rational beings. A careful reading of Kant's texts shows that he does not narrow the extension of the notion of dignity to the only species of homo sapiens. Hence, the second focus is about questioning anthropocentrism, for any being that meets specific rational autonomy criteria may be a bearer of dignity. According to Kant, there may even be super-personal bearers of dignity like the state. Kant, Oliver Sensen (2011) has pointed out, uses dignity in three different senses. First, for saying that one being is elevated over the others, e.g., the "monarch's dignity" (Streit der Fakultäten AA7: 19[27]; CE [Streit] 248), the "dignity of philosophy" (Kritik der reinen Vernunft B86, AA3:

142 http://heranet.info/about-us/who-we-are/hera-vision-2018-2022/, visited on 6 May 2021. 143 https://en.unesco.org/creativity/sites/creativity/files/passeport-convention2005-web2.pdf, visited on 6 May 2021.

144 https://www.un.org/en/about-us/universal-declaration-of-human-rights, visited on 6 May 2021. 
81[22]; CE [KrV] 199), the "dignity of mathematics" (Kritik der reinen Vernunft B492, AA3: 323[9-10]; CE [KrV] 496), the "worth of the teacher" (Religion innerhalb der Grenzen der blossen Vernunft AA6: 162[19]; CE [Religion] 184). Second, for expressing that human beings are elevated over the rest of nature in virtue of having freedom, "from the dignity of human nature, from its freedom" (Religion innerhalb der Grenzen der blossen Vernunft AA6: 57[26-27]; CE [Religion] 101), ${ }^{145}$ and third, for specifying that moral worth is unconditional, i.e., infinitely raised above price (Kato and Schönrich 2020, 164).

The Council of Europe has indicated the political actions needed for intercultural dialogue to advance through its white paper on intercultural dialogue, Living together as Equals in Dignity (Council of Europe 2008). Growing diversity in Europe is now a cultural reality, which should be considered and addressed individually and collectively. The democratic governance of cultural diversity should be "adapted in many aspects, democratic citizenship and participation should be strengthened, intercultural skills should be taught and learned, spaces for intercultural dialogue should be created, and intercultural dialogue should be taken to the international level" (EUR 2015, 5, 9). At stake is the promotion of social cohesion (Grant and Chapman 2008; Cai 2010).

It is time to move beyond the mere passive acceptance of multiple cultures co-existing in a society (inclusive society) and promote cultural diversity and intercultural dialogue (reflective society). Steven Vertovec has proposed to call "super-diversity" the interplay of factors such as "differential immigration statuses and their concomitant entitlements and restrictions of rights, divergent labour market experiences, discrete gender and age profiles, patterns of spatial distribution, and mixed local area responses by service providers and residents." Vertovec raises questions such as: How can the diversity of generations, gender, status, standard of living, and culture be considered? Is Europe a good thing, a resource for the member states and humanity, or does it present a risk of increasing tensions? Is the simple promotion of the universal values of human rights an adequate response to ensure equal treatment for all? How do we ensure that the wealth of cultural expression and languages does not disappear under the hegemony of political and economic issues and dominant cultural models? (Vertovec 2010, 66)

145 "Würde eines Monarches”-“Würde der Philosophie"-“Würde der Mathematik”-“Würde des Lehrers"-“Würde der menschlichen Natur, der Freiheit.” 


\subsection{Intercultural Dialogue}

The reflux of multiculturalism in countries that have applied it shows that recognizing cultural diversity can, in social and economic conditions of segregation and unemployment, generate conflicts (EAC 2014, 10-11). Intercultural dialogue is an "open and respectful exchange of views between individuals and groups belonging to different cultures that leads to a better understanding of the other's global perception" (EAC 2014, 16). Interculturalism differs from multiculturalism because it is not about the preservation and promotion of separated cultures. It is instead about mutual understanding and interaction (Dietz 2007). While the risk of multiculturalism is to reinforce isolation and conflict, intercultural dialogue bears hardly any risk, for it aims to strengthen social cohesion by creating bridges and links among people and communities. Intercultural competencies relate to key competencies such as communication in foreign languages, social and civic competencies, cultural awareness, and expression.

The issue boils down to "how do we understand how culture influences communication?” (Cai 2010, xxi) The way Kant has put it as regards the interplay of concepts and intuitions-following Kant's metaphor that "thoughts without content are empty, intuitions without concepts are blind" (Kritik der reinen Vernunft A51/B75, AA4: 48[13-14]/AA3: 75[14-15]; CE [KrV] 193-194) ${ }^{146}$-one might say that in the case of cultural diversity and intercultural dialogue reciprocity does not hold:

intercultural dialogue cannot exist without recognizing cultural diversity, while cultural diversity can exist without giving rise to intercultural dialogue.... Cultural diversity implies the existence of common characteristics of a group of people, such as language, religion, lifestyle, artistic expressions, relations between men and women, young and old, etc. All cultures are hybrid, mixed, infused. (EAC 2014, 9-10)

Intercultural dialogue aims to create a framework for relations between states, organizations, and people. What matters is the transformation of what circulates between people and how it transforms them because it is people, living in a complex society and speaking with their languages, customs, and beliefs that keep the dialogue alive-also, organizations, associations, businesses, cultural institutions, museums, libraries, archives, and community centers. While the recognition of cultural diversity belongs to human rights, intercultural dialogue aims to enable the sharing of experiences of common goods in spaces for exchange. Intercultural means questioning the content of what one transmits; it means ask-

146 "Gedanken ohne Inhalt sind leer, Anschauungen ohne Begriffe sind blind.” 
ing what one calls art, heritage, and self-expression (EAC 2014, 10). Some substantial challenges come up due to the intensity with which the dynamics of globalization have impacted not only on the flows of cultural goods, media products, and information as well as on migration:

\begin{abstract}
New forms of mobility have created new kinds of cultural juxtapositions, encounters, and exchanges, which have resulted in greater and more complex patterns of diversity within the European cultural space. Because these new forms of diversity and complexity are transnational and transcultural in their nature-functioning across national frontiersthey present a challenge for national policy frameworks. The established national mechanisms through which European states have hitherto managed cultural policy diversity and citizenship must now be supported by international or transnational strategies.... The challenge, at the beginning of the 21st century, must be to develop a democratic transnational and transcultural approach to cultural diversity policy in Europe. (Robins 2006)
\end{abstract}

How does migration affect the overall sentiment of a community? There is a need to quantify sentiment in the millions of tweets coming from different countries, which are the basis for comparing sentiment of various languages in the exact location that is geolocalized in other languages and compare the sentiment of the same language in multiple locations across areas with different levels of immigration (Coletto 2017). Currently, flows and stocks come from official data, which implies substantial delays in estimating migration, incorrect estimates, variations from one dataset to another. Through the approach of nowcasting, i.e., through real-time estimation, research can help policymakers build timely policies by estimating migration plans in the Twitter population (language, geolocation, social links) and subsequently by extrapolating the trends to the general population using accountable models, as pursued by Fosca Giannotti and her SoBigData team of at the Institute of Information Science and Technologies of CNR (ISTI). ${ }^{147}$

As Dana Diminescu has made clear, "this culture of bonds became visible and highly dynamic once migrants began massively to use modern information and communication technologies" (Diminescu 2008, 567). According to Ram Adhar Mall:

A peaceful encounter among religions, for example, demands that there must be room for a theory and practice of pluralism, even in the case of so-called revealed religions. Polytheism and pluralistic theology, rightly understood, are more tolerant and conducive to peace among religions than monotheism. This is because a pluralistic approach to the truth-secular or sacral-is by nature open and tolerant. A common conviction that cultures possess

147 http://sobigdata.eu, visited on 6 May 2021. 
basic similarities and illuminating differences that enable them that they meet to differ and defer to meet is a need of our age. (Mall 2015, 75)

We are at the beginning of a long and tenacious struggle. The theory and the practice of interculturality are bound to provide a substantial help: we need to individuate in the great reservoir of universalizing values those theoretical instruments and those forms of life that would make not only comparison among diverse cultural and religious options possible but also concur to the common grounding of the principles of freedom, equality, tolerance, and recognition of otherness (Cacciatore and D’Anna 2010).

\subsection{Dialogical Culture}

We are witnessing the paradigm change from a dialogue of cultures to a dialogically born culture. Before closing, let me leave the word to the Congregation for Catholic Education (2017), which has issued guidelines on Educating to Fraternal Humanism: Building a Civilization of Love that can be seen as a forerunner of the already mentioned encyclical letter Fratelli Tutti. ${ }^{148}$ As also maintained by Tu Weiming $(2018,1)$, dialogical culture does not stand for a mere exchange of views to know one another and mitigate the alienating effect of the encounter between citizens of different cultures. It must ignite an authentic dialogue within an ethical framework of requirements and attitudes for social objectives. The ethical requirements for dialogue are freedom and equality. Dialogue participants must be free from contingent interests. They must be prepared to recognize the dignity of all parties. These attitudes are supported by the consistency of dialogue with one's specific universe of values, which results in the general intention to match actions with words, in other words, to link the ethical principles we proclaim (e.g., peace, fairness, respect, democracy, etc.) with social and civic choices. We are looking at a grammar of dialogue, as pointed out by Pope Francis, that ought to be able to "build bridges and ... to find answers to the challenges of our time" (Congregation for Catholic Education 2017, 12-13).

In sum, considering the conceptual, cultural, and behavioral barriers to codesign (Jackson et al. 2018), initiatives ought to be taken by ministries, consulting organizations, teaching establishments at all levels, the media, museums,

$148 \mathrm{http} / /$ www.vatican.va/content/francesco/en/encyclicals/documents/papa-francesco_ 20201003_enciclica-fratelli-tutti.html, visited on 6 May 2021. 
public libraries, science centers, and organizations devoted to the promotion and sharing of experiences of common goods in public spaces. 
